\title{
Greek Medical Literature and its Readers
}

From Hippocrates to Islam and Byzantium

\section{Edited by \\ Petros Bouras-Vallianatos and Sophia Xenophontos}

First published 2017

3 The professional audiences of the Hippocratic Epidemics

Patient cases in Hippocratic scientific communication ${ }^{1}$

Chiara Thumiger

(CC BY-NC-ND 3.0) 
First published 2018

by Routledge

2 Park Square, Milton Park, Abingdon, Oxon OX14 4RN

and by Routledge

711 Third Avenue, New York, NY 10017

Routledge is an imprint of the Taylor \& Francis Group, an informa business

(C) 2018 selection and editorial matter, Petros Bouras-Vallianatos and Sophia Xenophontos; individual chapters, the contributors

The right of Petros Bouras-Vallianatos and Sophia Xenophontos to be identified as the authors of the editorial material, and of the authors for their individual chapters, has been asserted in accordance with sections 77 and 78 of the Copyright, Designs and Patents Act 1988.

With the exception of Chapters 3,6 and 9, no part of this book may be reprinted or reproduced or utilised in any form or by any electronic, mechanical, or other means, now known or hereafter invented, including photocopying and recording, or in any information storage or retrieval system, without permission in writing from the publishers.

Chapters 3, 6 and 9 of this book are available for free in PDF format as Open Access at www.tandfebooks.com. They have been made available under a Creative Commons Attribution-Non Commercial-No Derivatives 4.0 license.

Trademark notice: Product or corporate names may be trademarks or registered trademarks, and are used only for identification and explanation without intent to infringe.

British Library Cataloguing-in-Publication Data

A catalogue record for this book is available from the British Library

Library of Congress Cataloging-in-Publication Data

Names: Bouras-Vallianatos, Petros, editor.

Title: Greek medical literature and its readers : from Hippocrates to Islam and Byzantium / edited by Petros Bouras-Vallianatos and Sophia Xenophontos.

Description: Milton Park, Abingdon ; New York, NY : Routledge, 2018. | Includes bibliographical references and index.

Identifiers: LCCN 2017040874 | ISBN 9781472487919 (hbk : alk. paper) | ISBN 9781351205276 (ebk)

Subjects: LCSH: Medicine, Greek and Roman-History-Sources. |

Medical literature - Greece.

Classification: LCC R138 .G73 2018 | DDC 610.938-dc23

LC record available at https://lccn.loc.gov/2017040874

ISBN: 978-1-4724-8791-9 (hbk)

ISBN: 978-1-351-20527-6 (ebk)

Typeset in Times New Roman

by Apex CoVantage, LLC

THE CENTRE FOR HELLENIC STUDIES, KINGS COLLEGE

LONDON, PUBLICATION 20 


\title{
3 The professional audiences of the Hippocratic Epidemics
}

\author{
Patient cases in Hippocratic \\ scientific communication ${ }^{1}$
}

Chiara Thumiger

\section{Introduction}

The audience as determinant in the construction and understanding of a text has long entered the historiography of ancient literatures; ${ }^{2}$ in the field of the history of medicine (especially in its earlier phases, with their problematic compositional and transmission history), the exploration of audiences is a particularly important part of the equation in the attempt to fill in the void left by the fragmentation or instability of our sources' textual form. As van der Eijk has argued, ${ }^{3}$ formal and stylistic approaches to medical texts, in line with the more theoretically minded readings of other ancient literatures which are more commonly perceived as "canonic", or "high", are a much-needed move. This is not only the case for works clearly rich in authorial strategies, such as Galen's treatises, but also for those writings of the earlier period which had long been dismissed, outside the field of history of medicine, as "badly written" and only interesting as documents of rudimentary science. In this spirit, we shall then focus on medical texts as items in a communication, "speech acts" that can reveal information about their own target audiences, and concentrate on one specific group of texts belonging to the Hippocratic Corpus: the patient reports found in the seven books of the Epidemics.

As it is well known, the Epidemics are not consequential volumes composing a self-enclosed opus, but should instead be subdivided into three different blocks (Epid. 1-3; 5-7; and 2, 4 and 6) that display internal connections, and are among themselves of varying internal coherence and dating, ranging from the end of the fifth to the middle of the fourth century. ${ }^{5}$ What all seven books share, however, is a focus on human individuals, on the clinical dimension of the medical art. Over five hundred patients are mentioned in them - some of them within accomplished, diary-like case reports that monitor the illness from onset to death or recovery, others just brought in as examples, to provide a passing illustration for a medical point or draw parallels to other cases. Such a large quantity of references to individual clinical examples leaves the historian with questions which an audiencedirected inquiry is best equipped to answer. ${ }^{6}$ In particular: 1) Why did the ancients take such extensive record of individual cases, in particular in the early phase of Greek medicine? 2) What was the intended purpose, and who are the interlocutors of these reports - their audience - as they were recorded and drafted? 
3) In parallel to all these, which features in the form and presentation of the patient cases of the Epidemics can help us tackle these questions?

We shall begin by addressing the first two topics, in a comparative key. A brief consideration of the function of patient reports in current medical practices in dialogue with our ancient examples will prove very instructive in highlighting the distinctive characteristics of the ancient situation. We will then move to the third topic and explore some of the most notable formal features of the Hippocratic patient cases in terms of audience effect. In particular, I propose to interpret some of their most distinctive characteristics as expression of a mnemonic effort. This is part and parcel of a practice of medicine still largely based on oral learning and teaching, in which concrete details and direct experience had a much greater weight in proportion to theory than is the case for medical writings of the early centuries of our era; in these cases experience "grows out of sense perception aided by memory", to quote Jaeger's formula for the epistemology of the Epidemics. ${ }^{7}$ At the same time, the explicit intellectual engagement of the audience, of the "individual minds" of readers or listeners - the explicit demand to be remembered - stands out among all scientific genres, Western at least, as specific of medical literature of all times, precisely due to the urgency, and the consequences for human survival, that characterise medicine.

\section{Why take record of individual cases?}

It makes sense to approach our questions in comparative dialogue with the long tradition of case study in modern and contemporary medical training. The practice and study of patient stories - including case taking and the drafting of reports - are a fundamental part of the curriculum in medical schools and of the organisation of medical knowledge nowadays in the Western world at least. ${ }^{8}$ The subject of "history taking and examination" is an important part of the training as a medical student and features in undergraduate syllabuses as well as medical literature. ${ }^{9}$

The external presentation of some of the cases preserved in the Epidemics shows some strong analogies to contemporary practices. This is the case especially for those found in books 1 and 3, which are more elaborated and neatly concluded reports: ${ }^{10}$ a day-by-day (or anyway a regular) progression is often followed, with a section introducing the patient and the outcome at the end mostly made explicit. ${ }^{11}$ If there are analogies in content and structure, however, more important and telling for us are the differences in purpose and context between the Hippocratic practice and contemporary case reports. Medical activity nowadays and the clinical sphere in particular - the handling of patients - are fundamentally shaped by institutionalisation: hospital organisation and university programmes, protocols, career paths and hierarchies and the constraints posed by financial aspects (insurance policies and national health systems) and by legal ones (responsibility, standards of professional conduct and so on). All these determine the shape in which illnesses are recorded and define their audience: a medical-professional one, but also a bureaucratic, administrative entity and the patients themselves to an important extent. 
In ancient medicine, and especially in the classical era where our Epidemics cases were first written down, no such complex professional and institutional system was in place, and a clear-cut separation between laymen and professionals of the medical art was still absent from current social practices, as well as a matter of debate among the "scientific" physicians themselves. ${ }^{12}$ The question about the purpose and target of recording cases, then, needs to be answered exclusively in terms of intellectual motivation (scientific and didactic). There is no external lay party targeted, but the interlocutor remains internal to the group of physicians - those present, those consulting the reports at a second stage. The Epidemics patient reports are thus for us a precious document to the ancients' strategies for organising their medical knowledge and to their choice of the individually named case as epistemological form. This complete lack of any operational dimension allows us to see these cases as intellectual and epistemological material of a "purer" kind than the files and paperwork of modern hospitals; as such, they are best understood in terms of "thinking in cases", to quote Forrester's famous formula, a specific mode that occupies its own place in scientific thinking (as well as other areas, such as politics and law), ${ }^{13}$ descending from "Aristotle's practical wisdom". ${ }^{14}$ Forrester highlights how in the Hippocratic cases, despite their interest in individualisation, several general, doctrinal factors play a role (humours, hot and cold, and so on), thus locating them between empiricism and generalisation, and offering a first attempt to "standardised chronology" in their accounts of the course of individual illnesses. ${ }^{15}$ In our reading, we propose to look at the audiences of these texts as the primary, concrete reason for their existence in that precise form.

\section{What are the purpose and the interlocutors of case taking?}

The audience of patient reports is divided nowadays between 1) private, lay audiences, comprising the patients themselves and their families, plus non-medical third parties such as health care providers and financial entities, and 2) the professional and scientific audiences, consisting of attending physicians, recording their experiences for colleagues or for themselves for future use, students using the cases to learn clinical procedures and patient handling, and a larger scientific community debating cases of exceptional scientific interest - the highest representation of which is the so-called "grand round", the presentation of one case to a wide audience of medics in order to gather comments and disseminate results.

In the Hippocratic case reports, the targeted audiences and objectives are basically limited to the second receiving end, constituted by a scientific-professionaldidactic environment, ${ }^{16}$ and they are also fundamentally different in the form in which they are cast and in their epistemological function. The modern patient cases - but in this respect already the Galenic discussions of patients ${ }^{17}$ - belong to an approach to medicine that is rooted in a essentially fixed body of theoretical knowledge, one which is taken for granted as true and posited as foundational to the clinical activity. The individual case has a scientific raison d'être insofar as it is referred to this fixed body of knowledge, measured against it. Individual patients 
are diagnosed in previously known terms and based on postulated principles: this is evident, in current medicine, from the use of labels and protocols and, in the Galenic cases, in the deductive "detective narrative" that shapes them, where the doctor of exceptional competence and skill uncovers difficult diseases and hidden causes. ${ }^{18}$ While they all address medical audiences too, each of the three types of patient case (modern, Galenic and Hippocratic) has its own peculiarity not only as far as audiences are concerned, as we have seen, but also in the way in which audiences are involved. In the first two, the individual illustrates the general, is understood through the general, and only thanks to the physician's knowledge of the general is the patient treated in the best possible way. The Hippocratic texts, instead, are testimony to a much more open, fluid and tentative phase. The recording move is predominantly descriptive, and the information communicated is first and foremost an account of facts. As Grmek famously articulated, classical Greek medicine remained "diffident" towards that particular kind of empiricism that later allowed the development of the "scientific method" of proof and experiment. ${ }^{19}$ The observation of patients is here a matter of "taking stock" of experiences rather than interpreting and even extracting generalities from them. ${ }^{20}$ One should not dismiss, of course, the interest in patterns of disease and shared factors notably illustrated by the constitutions in Epidemics 1 and 3; the greatest emphasis in these clinical works, however, remains placed on the variety of details collected, rather than on their organisation into a comprehensive theory of disease. The Hippocratics' key interest is to register and preserve as much variety as possible, rather than associating it to rule or doctrine: to share an extended body of clinical experiences and scientific controversy with a wider audience of physicians and students, in what appears to be an effort towards a "virtual community" of scientists participating in the openness of attempts, mistakes, aporiai, and, sometimes, successes.

\section{What to remember? Ancient instructions for case taking}

Such openness, empiricism, descriptiveness and lack of theoretical engagement are alien to later casuistry in ancient medicine and make the Hippocratic approach a unicum at that in the history of Western science. Some explicit evidence is available in this connection, and in particular, there are three texts which effectively offer instructions about the items to observe and record during visits which are worth mentioning.

A first, famous passage is found at Hippocrates, Epidemics 1.23, which offers a list of items "to be observed":

From the custom, mode of life, practices and age of each patient, [data expressed by] words, manners, silence, thoughts, sleep or absence of sleep, nature and time of dreams, pluckings, scratchings, tears. ${ }^{21}$

A passage at Epidemics, 6.8.7-1522 is even clearer, as it alludes to the existence of a kind of "protocol". Here the author speaks of a certain "material from the

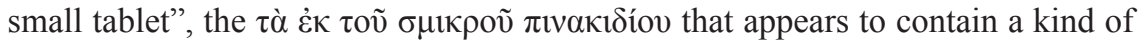




\section{Chiara Thumiger}

case-taking checklist, indicating the major $\sigma \kappa \varepsilon \pi \tau \varepsilon \dot{ } \alpha$, "things to observe". The list includes diet in all its aspects, sensorial perceptions, evacuations and behaviour of the patient; secretions of various kinds (7-8); at 9-10, heterogeneous data about sleep, dreams, the position of the bed, the general conditions of the environment and the mental life of the patient respectively; again factors related to age and the development of the individual (11), congenital and pathological factors (12), season (13) and factors typical of the diseases considered (14) and of the "epidemic" ones (15). From this rich "handbook" we detect little interest in generalisation the most evident sign of which would be a synthetic, diagnostic move; rather, the author prescribes the harvesting of details and gives guidelines on which topics should be remembered for the visit.

Along similar lines, On Humours too offers lists of things to observe. At $O n$ Humours 2 we read:

These things are to be observed: symptoms which cease of themselves, what is harmful or beneficial and in what cases, positions, movement, rising, settling, sleep, waking, which things are to be done or prevented, winds. Instructions about vomit, evacuation below, sputum, mucus, coughing, belching, flatulence, urine, sneezing, tears, itching, pluckings, touchings, thirst, hunger, repletion, sleep, pain, absence of pain, body, mind, learning, memory, voice, silence. $^{23}$

At On Humours 4, again we read:

The evacuations, whither they tend, without foam, with coction or cold, without coction, flatulent, dry and moist, bad smelling, thirst that was not present before, brought about neither by heat nor by any other cause, urine, wetness of the nostrils, prostration, dryness or fullness of the body and troubled respiration, hypochondrium, extremities, eyes sickly, change of complexion, pulsations, palpitations, chills, hardness of the skin, of the sinews, of the joints, of the voice, of the mind; voluntary posture; ... the dreams the patient sees, what he does in sleep, if his hearing be sharp, if he be interested in understanding information . . ${ }^{24}$

It is clear from these passages that patient observation (and reports, as a consequence) had to be detailed descriptions and that their audience and authors were basically identical subjects, professionals and repositories of medical authority. How could these remember such complex "to-do lists" during visit, and afterwards for drafting the report? How could this template be made to stick in the memory of students and physicians? We should now turn to the topic of memorisation and memory as part of the audience-directedness of these texts.

\section{Mnemonics and medical education}

The use of mnemonics is not unfamiliar to medical students even today, and indeed, it is recognised as very important in the study of medicine and in its practice. 
Currently employed textbooks and medical school material include lists of mnemonics for the memorisation of difficult lists, ${ }^{25}$ and an average standard text such as the International Handbook of Research in Medical Education ${ }^{26}$ discusses the "psychology of learning", emphasising the importance of acronyms (first-letter mnemonics) to train students' ability to remember lists of symptoms, names of anatomical parts and so on. Nowadays too, then, students (and then scientists) must rely on memory for key information that needs to be immediately retrieved when practising. This is the case for medics much more than for any other scientist, it is worth emphasising again, precisely due to the pragmatical, operational component of medicine and of the "urgency" factor that typifies it.

Of course, all written-down data presuppose memorisation and are aimed at recollection, in any text, not only medical or even technical. In the case of medical knowledge articulated in cases, however, this is true in a more concrete and visible sense. The physician needs to remember the right questions and areas of inquiry, and the data gathered from the examination, and short-hand them. Many details, some of them even idiosyncratic and trivial, are noted as they populate the picture of personal vividness - the difference between arid facts and human data and especially, I argue, since they function as future mnemonics for the physician, they help him remember specific clinical facts, successful procedures, dangers, unexpected reactions and so on. ${ }^{27}$

This mechanism holds good for today's physician as well as for their ancient counterparts. Nonetheless, mnemonics in contemporary practices (with their availability of written records and information) has a different, curtailed role compared to the ancient state of affairs. In the classical era written transmission was still an exception and parallel, rather than alternative to oral culture. ${ }^{28}$ In such a context memorisation belongs to the purpose of any text, and effects aimed at enhancing memorability - for the performer, audience or both - are in fact embedded in all genres of antiquity. Ancient testimonies clearly show awareness of the importance of mnemonics - take Cicero's anecdote about Simonides' ability to remember the name and place of all guests at a large banquet, by resorting to a "mental image". ${ }^{29}$ There are, surely, important differences from the explicitly stated aims of communication, say, in oratory - to persuade; in epic - to entertain; in tragedy - to engage emotionally and intellectually and teach at a moral and spiritual level (these, of course, not discounting combinations and overlaps, nor banalising the other socio-cultural levels on which all these genres operate). In the case of medicine, memorability has a specific operative application - to allow reproduction of the same actions or to avoid them - and had to be attached to the individuality of the one case as event, rather than to an artistic sequence of words, a poetic effect, a rhyme or a story of beauty.

The mnemonics ancient medical audiences needed and employed were also very different from contemporary medical mnemonics, mostly first-letter acronyms, although both are motivated by the urgency of recalling needed knowledge. A glimpse into a similar expedient, although allowing only a partial comparison is a notable feature of the preserved manuscripts of Epidemics 3, namely the "characters" that are found in some manuscripts at the end of patient reports in this book. These letters, which were known to Galen and regarded already by him 


\section{Chiara Thumiger}

as not original, appear to be a form of shorthand, to the purpose of summing up notable features of each case: $Y$ or $\Theta$ for life and death respectively, A for "miscarriage" or "destruction", $M$ for "madness" or "womb", $\Phi$ for "phrenitis" or "consumption" and so on. ${ }^{30}$ These signs give us some insight into the use and responses of professional audiences to these cases and into possible strategies to summarise them and make them readily available for consultation by assigning token signs.

The addition of these characters on the manuscripts of Epidemics 3 remains, however, a later and rather unique piece of evidence in the direction of extracting a diagnosis or assigning a pathological category to individual patient cases. It is, rather, the vividness and sometimes narratological ${ }^{31}$ complexity in the text itself of the Hippocratic cases that has the effect of reminding doctors of the collected data, through the idiosyncratic mnemonic trigger of a face, a place, a human detail. This "representational" project, the drawing of these "scenes" is closely allied to the scientific objective, since their point is precisely to allow the transmission of particular information.

In short, through these case reports, the medical author sought, among other things, to present medical knowledge in a mnemonically viable form, so as to offer students and colleagues a repertoire of concrete examples of the doctrines studied and the practices recommended. The appeal to individuality in patient cases is thus altogether different from that characterising current forms of case recording - aimed at legal-financial purposes or part of the privacy-minded record each legal subject in our world is entitled to. Rather, it is an individuality of an epistemological kind, serving exclusively the observer, not the observed. What in current medicine is only one half of the role of case taking is in Hippocratic medicine the centre of the practice.

\section{Ancient mnemonics in the form of patient cases}

To better illustrate this, let us follow the acceptable indications of a psychology manual currently in use, ${ }^{32}$ according to which key mnemonic expedients are:

- the use of mental pictures;

- $\quad$ to form bizarre, unusual or exaggerated mental connections;

- to make information familiar; and

- $\quad$ to make things meaningful.

When we look at patient cases in terms of memorisation, recollection and mnemonics, a yet more fundamental difference between ancient and modern times becomes evident: the modern reliance on the precise, steadfast and readily available backup of written details versus the blind field in which the Hippocratic physician had to work. This is not an accessory fact: reflection on, and recollection of, individuals pose entirely different challenges and presuppose entirely different motivations when not backed by the bureaucracy and documentation that frame modern citizenship. 


\section{The use of mental pictures}

First of all, the emphasis on names, addresses and anagraphics of various sorts. These vary a lot in the Epidemics but in most cases convey a strong sense of individuality. In Epidemics 1-3, names are real ones, often with address: e.g. at Epidemics 1.26, case 1: "Philiscus lived by the wall", ${ }^{33}$ case 2: "Silenus lived on Broadway near the place of Eualcidas"34 and case 8: "Erasinus lived by the gully of Boötes". ${ }^{35}$ In some cases definitions based on where a patient was found are used (Epidemics 1.26, case 5: "the wife of Epicrates, who lay sick near the (statue/temple of) the founder"; ${ }^{36}$ case 6: "Cleanactides, who lay sick above the temple of Heracles"; case 10: "the man of Clazomenae, who lay sick by the well"; 37 case 13: "a woman lay sick by the shore"; 38 and case 14: "Melidia, who lay sick by the temple of Hera"); ${ }^{39}$ sometimes the people patients are staying with are recalled: Epidemics 3.1.5, "Chaerion, who lay sick in the house of Demaenetus" ${ }^{40}$ case 7: "the woman ... who lay sick in the house of Aristion", ${ }^{41}$ case 9: "the woman who lodged with Tisamenus", ${ }^{42}$ and case 10: "a woman who was out of the house of Pantamides". ${ }^{43}$ Names, places, relations: what is the point in this systematic precision (all patients in Epidemics 1-3 are qualified in one of the ways above) in a medical culture where bureaucratic data gathering played no role? The function of these labels is precisely to allow memorisation and visualisation of each occurrence.

\section{To form bizarre, unusual or exaggerated mental connections}

More clearly relevant still to our purpose are the cases in Epidemics 2, 4 and 6 , which we have seen to have a more conspicuous "didactic" component: here names are mostly absent, and their indication is replaced by periphrases with idiosyncratic and realistic details, whose mnemonic function is overt: "the wife of the leatherworker who made my shoes"; the "woman with pain in the hips" (Epidemics $2.2,17,18) ; 4$ " "the men whose head I opened" and "the man whose calf was cut" at Epidemics 4.1;4 "the ropemaker", "the branded slave" at Epidemics $4.2 ; 46$ "the Chalcedonian carried from the gates to the agora. . . ." at Epidemics 4.3; "the wool carder" at Epidemics $4.36 ; ;^{48}$ and "the newly purchased servant girl whom I saw" at Epidemics $4.38{ }^{49}$ In Epidemics 6 we also find periphrases: "the man stretching while twisting the vine pole" at Epidemics $6.3 .8,{ }^{50}$ or "the one who was corroding on the head" at Epidemics 6.4.5, ${ }^{51}$ or "the man to whom Cyniscus brought me" at Epidemics 6.7.10. ${ }^{52}$ The sense of these is to create a viable, memorable anecdote for students and scientists to easily recollect or picture consider also the unique mention of a (possibly comic) nickname in Epidemics 6.8 .29$, , "Satyros, in Thasos, nicknamed "the griffinfox" ${ }^{54}$

\section{To make information familiar}

A passage at Hippocrates, Epidemics 6.2.24, ${ }^{55}$ recommends which specific themes should be addressed during a visit: "dispositions about the patient" and 
"questioning" him, or her, and accordingly taking notice of "what he tells, what kind of things, how he should be received"; his or her reasoning, or words; "what relates to the patient, what relates to those who are present, and to people elsewhere". Questioning the patient is important, claims this physician, and the interrogation must explore the larger context of the sick person. A kind of sociology and psychology of the patient seems to be recommended, of the kind case taking nowadays involves, aimed at assessing the life conditions and psychological environment of patients. When we compare, however, these indications with the fact that details about relationships and general social status are not paramount (indeed, they are absent, except from the mention of slaves) in any of the cases we have, ${ }^{56}$ we are drawn to another interpretation of the recommendation that has to do with the audience and with the later use or uses of the texts: these interpersonal details are better explained by invoking a mnemonic purpose - they are ways to create that familiarity of the patient that allows recollection at the same time. ${ }^{57} \mathrm{In}$ the same spirit we can interpret details at first sight less significant, such as the specification, describing the sixth day of the illness of the wife of Theodorus, that abundant sweating occurred at a precise moment of the day, "around the time of the filling of the marketplace", ${ }^{58}$ arguably also an expedient to fix a critical event into memory.

Other features one may define as "emotional" can be seen in the same light, lacking any other functional justification: "the beautiful daughter of Nerios" is a remark that seems to function as a mnemonic token by appealing to the emotional effect of a beautiful young girl, especially as she "dies on the ninth day". 59 A different kind of emotionality is that of professional and scientific suspense; in the mistaken prognosis of Timocrates in Epidemics 5.2, the patient "did not seem in his sleep to those who were there to be breathing, but to have died. He perceived nothing, speech or action, and his body was stretched out and rigid. But he survived and woke up"; ${ }^{60}$ or in the case at Epidemics, $5.46,{ }^{61}$ where the patient survived "against all expectations" ( $\pi \alpha \rho \alpha \delta$ o $\xi$ ó $\alpha \tau \alpha \dot{\varepsilon} \sigma \omega \dot{\theta \eta})$. Associating a case to a challenging, critical moment ensures its notability for future recollection.

\section{To make things meaningful}

Another mnemonic avenue, finally, is the highlighting of the intellectual dimension of the medical challenge, to connect it to scientific effort and discussion, thus associating it with "meaning". The most powerful tool in this sense is the reference to controversy. A mnemonic network, in fact, is also created by the frequency with which the work of fellow doctors is critically mentioned - sometimes approved of, more often criticised; one's mistakes are also sometimes admitted, effectively staging a medical "programme". ${ }^{62}$ The most conspicuous examples for such effect are found in Epidemics 2, 4 and 6, and to a lesser extent in Epidemics 5 and 7.63 For instance, at Epidemics $7.123,{ }^{64}$ the doctor is criticised: "the doctor did not realise" (and the patient died); at Epidemics 5.14, ${ }^{65}$ we read that "it seemed to the doctors that it was peripleumonia, but it was by no means the case"; at Epidemics $5.28,{ }^{66}$ it is said that a case "was rightly recognised as needing trephination". 
All these involve the professionals present there, as well as add tridimensionality to the reports by evoking the ambiguity and problems of the individual case, its cognitive and scientific complexity. Caution or modesty is just a different modality of the same inclusion of self and internal audience which enhance memorability and reader engagement - "I, for one, thought that. . ." and the like. For instance, at Epidemics 5.95, ${ }^{67}$ "it seemed to me that the physician who took out the spear left a piece of the shaft in the diaphragms. Since he was in pain, the physician gave him an edema towards evening and a drug by the bowel . .." ${ }^{68}$

As readers are engaged with the debate and its very practical consequences, professional choices and clinical practices are anchored to a unique and thus unforgettable scene, which is the information the doctors are interested in. These intersecting scientific opinions and professional subjects create a vivid, dramatic act that bring experience back to life and make it memorable: it is not the name of a disease, or the efficacy of one drug that is at the centre, but a repertoire of details, a full experience that is shared through the reports with students and colleagues.

\section{Questions and teaching}

Questions are a feature of didactic exchange; it is obvious that they are instrumental to mnemonic acquisition. These are especially found in Epidemics 2: e.g. at Epidemics 2.2.9b: "question: is it easier always to satiate with drink or with food?" ${ }^{69}$ and at Epidemics 2.2.10: "how can one recognise very serious pains?". ${ }^{70}$ These are general points - but strictly practical, not theoretical; there are also clinical questions attached to individual cases, e.g. Epidemics 2.3.11: "does such excrement indicate crisis, as did that of Antigenes?". ${ }^{71}$ At Epidemics, 7.57: "is it true that in all suppurations, including these around the eye, the distress comes towards night?". ${ }^{72}$

There are a few similar examples in the Epidemics and in other texts which preserve clinical material, such as Prorrhetic $1,{ }^{73}$ another text dated to the classical period. These questions are a useful element to analyse the history of medical audiences and medical intellectual debates. The format, in fact, while fitting an occasion of learning and a circumstance of oral exchange, becomes also the shape of a specific technical genre, of which the Aristotelian Problemata are the most obvious example: that of scientific open questions which offer both a list of topics for discussions and a repertoire of genuine interrogatives about physical topics. Later texts show the influence of this style of scientific transmission, ${ }^{74}$ thus rendering inadequate a simplistic classification of it in terms of orality alone. ${ }^{75}$ What was in the Epidemics more directly dependent on the oral context of data collection and composition persists as style of scientific writing precisely by virtue of its mnemonic effectiveness. ${ }^{76}$

\section{Conclusion}

In a very explicit way, the patient cases in the later group of Epidemics expose the traffic in and out, so to speak, in the creation of the patient narratives: the disease, 
the patient and the operating physicians are the main actors in the story, but a complication of competing voices and ears contribute to the form of the patient reports as we have them, giving them depth and shaping them to fit a present, but most of all a future didactic and scientific transmission. The later audience of the cases, or the practising and recording physician projecting his audience, participate in the creation of the text as well as constituting its ultimate receiver.

To summarise our findings, the Hippocratic Epidemics case reports is an example of a text whose intended audiences, despite the ambiguities and historical uncertainties about the texts' composition and transmission, were very firmly delimited as professional and medical. Such closure defines this phase of ancient medicine as particularly territorial and "technical", on the one hand - no literary pretence, nor broader intellectual appeal of the kind shown by Galen is on the horizon of these writers, nor any explicit attempt to win over lay audiences, at least in the Epidemics. ${ }^{77}$ Also, it tells us something about the epistemology and didactics at work in the Hippocratic handling of patients, which we can summarise as follows: non-theoretical, observation-based and data-centred; self-standing, i.e. not relying on a system of knowledge or a "syllabus" (compare Galen's frequent recommendation on which of his books one should read first, which are for beginners, what should follow, etc.), but needing to "support itself" by insuring the memorisation of the repertoires of observations, procedures, risks and mistakes; lack of a synthesis of the empirical data, such as a form of diagnosis, or of the "epistemological extension" that might turn the observed case into an "experiment" ${ }^{78}$ The Hippocratic use of individual evidence - the patient case remained in this early stage a communication of pure data. Individual memory, in conclusion, the reception of an individual intellect - a future student, a training doctor - characterises the audience of these texts, motivates and even determines, concretely, their very existence.

\section{Notes}

1 I would like to thank the organisers of the conference, Petros Bouras-Vallianatos and Sophia Xenophontos, for inviting me to present this paper and offering their useful feedback, and the audience at the conference for their insights and criticism; Lutz Graumann for discussion about current medical case taking; the anonymous reader at the press; and last but not least, the Alexander von Humboldt project directed by $\mathrm{Ph}$. Van der Eijk and the Wellcome Trust who funded my research during the time in which I worked on this study in its various versions.

2 See Taplin (2000: 1-5) for a statement embracing history of ancient literature as a whole; Werner Jaeger in his Paideia (1944: 3-45), in the chapter on "Greek medicine as education", was the first to offer a perspective in this sense with reference to medicine, which remains fundamental.

3 Van der Eijk (1997: 79-121).

4 See van der Eijk (1997: 83).

5 See Jouanna (1999: 387-90) and Craik (2015: 63-91) for details.

6 Van der Eijk (1997: 86-9).

7 Jaeger (1944: 20). 
8 See Böhm, Köhler and Thome (1978) and the various reflections on this genre, its techniques and methodological challenges in Hunter (1991); Good (1994); Del Vecchio Good (1995); Frank (1995); Greenhalgh and Hurwitz (1999); Brody (2003).

9 Just representatively: the UCL "Guide to history taking and examination" at www.ucl.ac.uk/pcph/undergrad/cbt/year4/history-and-examination (accessed 18 February 2017).

10 See Hellweg (1985) and Lichtenthaeler (1994) for an analysis of the formal features of these cases and their heavier authorial hand.

11 One short example: [Hippocrates], Epid., 1.26, case 2, ed. Littré (1840) II.684-6 = ed. Kühlewein (1894) 203.11-204.1:

Silenus lived on Broadway near the place of Eualcidas. After over-exertion, drinking, and exercises at the wrong time he was attacked by fever. He began by having pains in the loins, with heaviness in the head and tightness of the neck. From the bowels on the first day there passed copious discharges of bilious matter, unmixed, frothy, and highly coloured. Urine black, with a black sediment; thirst; tongue dry; no sleep at night. Second day. Acute fever, stools more copious, thinner, frothy; urine black; uncomfortable night; slightly out of his mind. Third day. General exacerbation; oblong tightness of the hypochondrium, soft underneath, extending on both sides to the navel; stools thin, blackish; urine turbid, blackish; no sleep at night; much rambling, laughter, singing; no power of restraining himself. Fourth day. Same symptoms. Fifth day. Stools unmixed, bilious, smooth, greasy; urine thin, transparent; lucid intervals. Sixth day. Slight sweats about the head; extremities cold and livid; much tossing; nothing passed from the bowels; urine suppressed; acute fever. Seventh day. Speechless; extremities would no longer get warm; no urine. Eighth day. Cold sweat all over; red spots with sweat, round, small like acne, which persisted without subsiding. From the bowels with slight stimulus there came a copious discharge of solid stools, thin, as it were unconcocted, painful. Urine painful and irritating. Extremities grow a little warmer; fitful sleep; coma; speechlessness; thin, transparent urine. Ninth day. Same symptoms. Tenth day. Took no drink; coma; fitful sleep. Discharges from the bowels similar; had a copious discharge of thickish urine, which on standing left a farinaceous, white deposit; extremities again cold. Eleventh day. Death.

Here and throughout, English translation of the Epidemics 1, 3 and 2, 4-7 are by Jones (1923) and Smith (1994) respectively, with adjustments.

12 See, in this respect, Thumiger (2016: 199-200) on the fluid boundaries between "popular" and "scientific medicine" in ancient culture, especially in the classical era; Harris (2016) for an important and full methodological discussion.

13 Forrester (1996: 13-14) for a brief "history" of the medical case.

14 Forrester (1996: 21).

15 Forrester (1996: 13), who, however, did not otherwise devote much space to the Hippocratics in his discussion.

16 This is the case especially for the clinical texts of the Epidemics; other Hippocratic treatises admit the presence of laymen among their addressees, for instance On Regimen and On Internal Affections, which involve the understanding of intelligent nonprofessionals, or On the Sacred Disease which offers philosophical comments we can imagine to be in line with current intellectual trends and addressed to a wider audience. The intellectual milieu of Hippocratic medicine and its transmission has long attracted scholarly attention: see Deichgräber (1933) and (1982), and Langholf (1990) on the Epidemics; Jouanna (1999: 75-112) for an introduction; most recently, important contributions focused on the aspects of Hippocratic "teaching" and scientific communication have appeared in Horstmanshoff (2010); van der Eijk (2005: 121-236). 
17 See Lloyd (2009).

18 See Lloyd (2009: 124-5) on "success" as distinctive feature of the Galenic cases.

19 Grmek (1996).

20 On these characteristics, see Lloyd (2009: 121, 130-1).

21 [Hippocrates], Epid., 1.23, ed. Littré (1840) II.670.5-9 = ed. Kühlewein (1894)

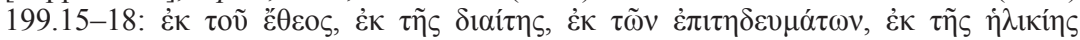

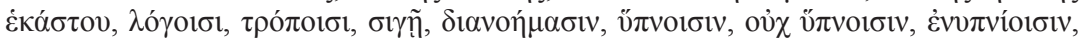
oĭoıเ edition alongside the Littré reference, I follow naturally the modern text.

22 [Hippocrates], Epid., 6.8.7-15, ed. Littré (1846) V.344-17-348.22 = ed. ManettiRoselli (1982) 167.1-179.3. I agree with Manetti and Roselli (1982: 167-8) to take these paragraphs as a block; see also their comments on these "tablets"; on the scholarly interpretations and their significance, see Alessi (2010: 127, with n. 16).

23 [Hippocrates], Hum., 2, ed. Littré (1846) V.478.6-13 = ed. Overwien (2014) 160.3-8:

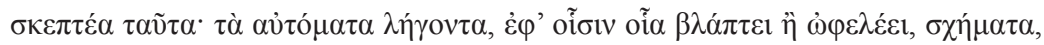

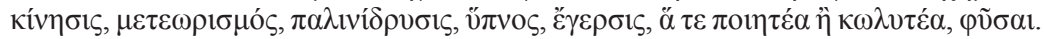

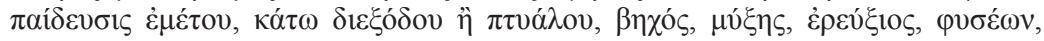

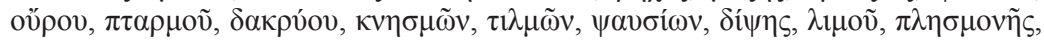

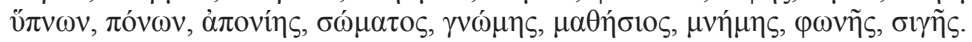

24 [Hippocrates], Hum., 4, ed. Littré (1846) V.480.13-482.5 = ed. Overwien (2014) 162.1-8:

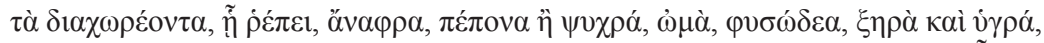

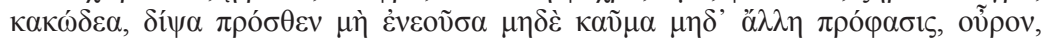

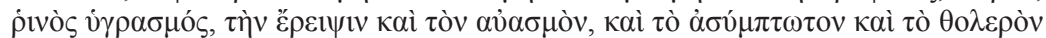

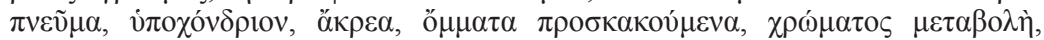

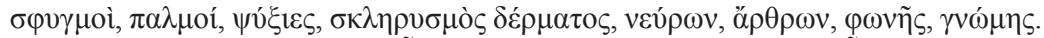

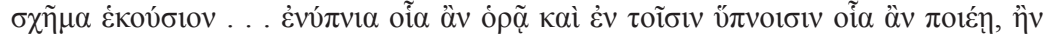

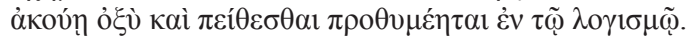

25 For example, www.oxfordmedicaleducation.com/medical-mnemonics/ (accessed 18 February 2017). I thank Katherine van Schaik for discussion on this.

26 Norman et al (2002: 185-6).

27 As van der Eijk (1997: 98) clearly describes: "[T]he empirical data reflected in case histories such as the Epidemics must soon have reached such vast proportions and such a high degree of detail that it could not possibly be remembered; so there was a need for storage of information based on the belief that such information might remain useful".

28 This is of course too large a topic to exhaust here: on the shift from oral culture to written transmission as causal force in determining the characteristics of Hippocratic scientific thought, see Lonie (1983), Miller (1991: 11-13) for the status quaestionis; van der Eijk (1997: 93-9) correctly reformulates the issue, indicating the written record itself as the consequence of "a new attitude towards knowledge", a knowledge seen as "a common reservoir of knowledge accessible to a group of physicians . . . and admitting of additions and changes by this group of physicians" (1997: 98); Langholf (2004: 222), who addresses the Havelockian approach to Homer as model for the medical material and traces the presence, in the fifth- and fourth-century "Hippocratic" texts, of modes of communication that have still much in common with oral production and delivery.

29 Cicero, Or., 2.86.352-4: locos esse capiendos et ea, quae memoria tenere vellent, effingenda animo atque in iis locis collocanda ("one must select localities and form mental images of the facts they wish to remember and store those images in the localities"), transl. by Sutton (1942); on the so-called "method of loci", cf. [Cic.], Rh. Her. 3.16-24; Aristotle, Top., 452a13-16. 
30 See Jones (1923: 213-7), quoting Galen, Comm. Hipp. Epid. III, 2.4, ed. Kühn (1828) XVIIA.611-3 = ed. Wenkebach (1936) 81.22-83.13.

31 Thumiger (2015a) and (2015b).

32 Coon (2005: 326).

33 [Hippocrates], Epid., 1.26, ed. Littré (1840) II.682 = ed. Kühlewein (1894) 202.

34 [Hippocrates], Epid., 1.26, ed. Littré (1840) II.684 = ed. Kühlewein (1894) 203.

35 [Hippocrates], Epid., 1.26, ed. Littré (1840) II.702 = ed. Kühlewein (1894) 209.

36 [Hippocrates], Epid., 1.26, ed. Littré (1840) II.694 = ed. Kühlewein (1894) 206.

37 [Hippocrates], Epid., 1.26, ed. Littré (1840) II.704 = ed. Kühlewein (1894) 210.

38 [Hippocrates], Epid., 1.26, ed. Littré (1840) II.712 = ed. Kühlewein (1894) 213.

39 [Hippocrates], Epid., 1.26, ed. Littré (1840) II.716 = ed. Kühlewein (1894) 214.

40 [Hippocrates], Epid., 3.1, ed. Littré (1841) III.46 = ed. Kühlewein (1894) 219.

41 [Hippocrates], Epid., 3.1, ed. Littré (1841) III.52 = ed. Kühlewein (1894) 221.

42 [Hippocrates], Epid., 3.1, ed. Littré (1841) III.58 = ed. Kühlewein (1894) 221.

43 [Hippocrates], Epid., 3.1, ed. Littré (1841) III.60 = ed. Kühlewein (1894) 222.

44 [Hippocrates], Epid., 2.2, 17, 18, ed. Littré (1846) V.90.7-13 = ed. Smith (1994) 34.

45 [Hippocrates], Epid., 4.1, ed. Littré (1846) V.144.3 = ed. Smith (1994) 86.

46 [Hippocrates], Epid., 4.2, ed. Littré (1846) V.144.9-12 = ed. Smith (1994) 86.

47 [Hippocrates], Epid., 4.3, ed. Littré (1846) V.144.17-18=ed. Smith (1994) 89.

48 [Hippocrates], Epid., 4.36, ed. Littré (1846) V.178.10 = ed. Smith (1994) 123.

49 [Hippocrates], Epid., 4.38, ed. Littré (1846) V.180.5 = ed. Smith (1994) 123.

50 [Hippocrates], Epid., 6.3.8, ed. Littré (1846) V.296.5-6 = ed. Manetti-Roselli (1982) $60.1-2$.

51 [Hippocrates], Epid., 6.4.5, ed. Littré (1846) V.308.7 = ed. Manetti-Roselli (1982) 84.11-2.

52 [Hippocrates], Epid., 6.7.10, ed. Littré (1846) V.342.8-9=ed. Manetti-Roselli (1982) 162.5-6.

53 [Hippocrates], Epid., 6.8.29, ed. Littré (1846) V.354.6-9 = ed. Manetti-Roselli (1982) 190.5-192.3.

54 On this nickname, see Thumiger (2017a).

55 [Hippocrates], Epid., 6.2.24, ed. Littré (1846) V.290.4-6 = Manetti-Roselli (1982)

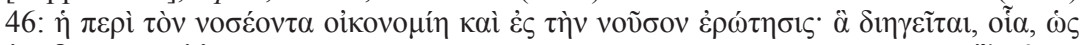

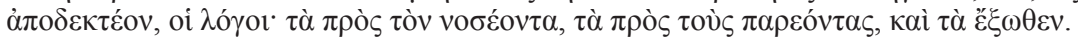

56 See Thumiger (2017a) details on what there is on the topic.

57 See Manetti-Roselli ad loc. (1982: 47) on this passage as expressive of the importance of the patient's words.

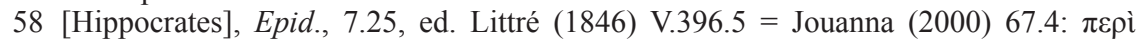

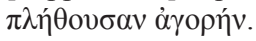

59 [Hippocrates], Epid., 5. 50, ed. Littré (1846) V.236.11 = ed. Jouanna (2000) 23.15: $\dot{\eta}$

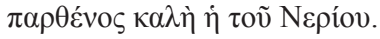

60 [Hippocrates], Epid., 5.2, ed. Littré (1846) V.204 = ed. Jouanna (2000) 3.2-5: غ̇v $\delta \dot{\varepsilon}$

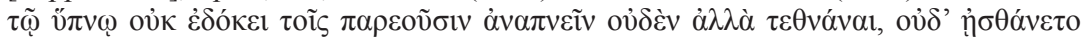

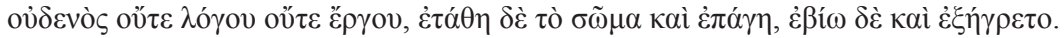

61 [Hippocrates], Epid., 5.46, ed. Littré (1846) V.234.9-10 = ed. Jouanna (2000) 22.8.

62 With Alessi's label (2010).

63 See Alessi (2010) on this; Manetti (1990: 149) on some important questions on the topic, with reference to Epid. 2.

64 [Hippocrates], Epid., 7.123, ed. Littré (1846) V.468.5-6 = ed. Jouanna (2000) 118.4: ó iๆ

65 [Hippocrates], Epid., 5.14, ed. Littré (1846) V.212.20-1 = ed. Jouanna (2000) 8.19-20.

66 [Hippocrates], Epid., 5.28, ed. Littré (1846) V.226.20 = ed. Jouanna (2000) 17.14:

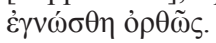

67 [Hippocrates], Epid., 5.95, ed. Littré (1846) V.254.19-256.1 = ed. Jouanna (2000)

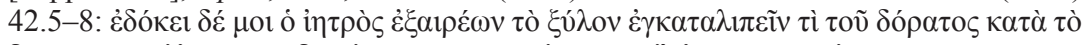

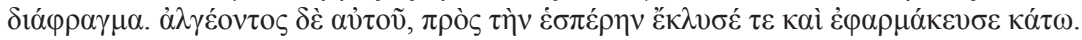




\section{Chiara Thumiger}

68 See on this Thumiger (2015b) and (2017b).

69 [Hippocrates], Epid., 2.2.9b, ed. Littré (1846) V.88.11 = ed. Smith (1994) 35:

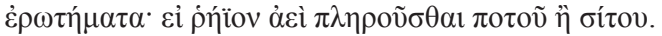

70 [Hippocrates], Epid., 2.2.10, ed. Littré (1846) V.88.13-14 = ed. Smith (1994) 32:

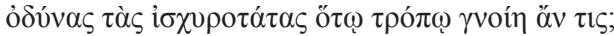

71 [Hippocrates], Epid., 2.3.11, ed. Littré (1846) V.114.8-9 = ed. Smith (1994) 59. With Smith's reading.

72 [Hippocrates], Epid., 7.57, ed. Littré (1846) V.424.5-6 = ed. Jouanna (2000) 86.4-6

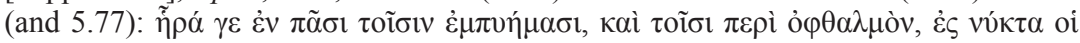

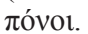

73 See Oikonomopoulou (2015: 70-1) on Hippocratic parallels to the Aristotelian Problemata and on questions in ancient medical literature.

74 Its influence may be found, for instance, in Galen's On Problematical Movements, as noted by Nutton (2015: 342); see (Nutton 2015: 342-3) on "problem literature" as genre and on its general features. See Oikonomopoulou (2015) for theoretical remarks on the structure and organisation of the Aristotelian Problemata; and Meeusen (Chapter 5), in this volume, on the example of pseudo-Alexander of Aphrodisias' Medical Puzzles.

75 On this, see n. 28 above.

76 Compare the fundamental role played by testing and questions in scientific teaching nowadays (one example, www.testprep-online.com/teas-science) (accessed 18 February 2017); teachers' instructions take questioning for granted as part of the activity of teaching, not only of assessing students: "Historically, teachers have asked questions to check what has been learnt and understood, to help them gauge whether to further review previous learning, increase or decrease the challenge, and assess whether students are ready to move forward and learn new information (factual checks - i.e. 'Closed' questions). This can be structured as a simple 'teacher versus the class' approach (Bat and Ball), where the teacher asks a question and accepts an answer from a volunteer, or selects/conscripts a specific student to answer. These approaches are implicit in any pedagogy, but teachers need a range of 'Open' questioning strategies to address different learning needs and situations". (www.nsead.org/downloads/Effective_Questioning\&Talk.pdf [accessed 18 February 2017]).

77 See $n .16$ above.

78 See above p. 51.

\section{Bibliography}

\section{Texts and translations used}

Jones, W. H. S. (ed. and tr.). 1923. Epidemics 1, 3. Cambridge, MA: Harvard University Press.

Jouanna, J. (ed. and tr.). 2000. Epidémies 5 et 7. Paris: Les Belles Lettres.

Kühlewein, H. (ed.). 1894. Hippocratis opera omnia I. Leipzig: Teubner.

Kühn, C. G. (ed.). 1821-33. Claudii Galeni Opera omnia. 20 vols. in 22. Leipzig: Knobloch.

Littré, E. (ed.). 1839-61. Oeuvres complètes d'Hippocrate: traduction nouvelle avec le texte grec en regard, collationné sur les manuscrits et toutes les éditions; accompagnée d'une introduction, de commentaires médicaux, de variantes et de notes philologiques; suivie d'une table générale des matières. 10 vols. Paris: J.-B. Baillière.

Manetti, D. and A. Roselli. (eds. and trs.). 1982. Ippocrate. Epidemie. Libro sesto. Florence: La Nuova Italia Editrice.

Nutton, V. (ed. and tr.). 2015. Galen. On Problematical Movements. Cambridge: Cambridge University Press. 
Overwien, O. (ed. and tr.). 2014. Hippocratis de humoribus. Berlin: De Gruyter.

Smith, W. D. (ed. and tr.). 1994. Epidemics 2, 4-7. Hippocrates. Cambridge, MA: Harvard University Press.

Sutton, E. W. and H. Rackham. (eds. and trs.). 1942. On the Orator: Books 1 and 2. Cambridge, MA: Harvard University Press.

Wenkebach, E. (ed.). 1936. Galeni In Hippocratis Epidemiarum librum III commentaria III. Leipzig et Berlin: Teubner.

\section{References}

Alessi, R. 2010. 'Research Program and Teaching Led by the Master in Hippocrates Epidemics 2, 4 and 6', in M. Horstmanshoff (ed.), Hippocrates and Medical Education. Leiden: Brill, 119-36.

Böhm, K., Köhler, C. O. and R. Thome. 1978. Historie der Krankengeschichte. Stuttgart: Schattatauer.

Brody, H. 2003. Stories of Sickness. Oxford: Oxford University Press.

Coon, D. 2005. Psychology: A Modular Approach to Mind and Behavior. Andover, MA and Hampshire: Wadsworth Publishing.

Craik, E. M. 2015. The 'Hippocratic Corpus': Content and Context. London and New York: Routledge.

Deichgräber, K. 1933. Die Epidemien und das Corpus Hippocraticum: Voruntersuchungen zu einer Geschichte der Koischen Ärzteschule. Berlin: Abhandlungen der Preußischen Akademie der Wissenschaften.

- 1982. Die Patienten des Hippokrates: historisch-prosopographische Beiträge zu den Epidemien des Corpus Hippocraticum. Mainz: Steiner.

Del Vecchio Good, M.-J. 1995. American Medicine: The Quest for Competence. Berkeley, CA: University of California Press.

Eijk, P. van der. 1997. 'Towards a Rhetoric of Ancient Scientific Discourse Some Formal Characteristics of Greek Medical and Philosophical Texts', in E. J. Bakker (ed.), Grammar as Interpretation: Greek Literature in its Linguistic Contexts. Leiden: Brill, 77-129. . (ed.). 2005. Hippocrates in Context. Papers read at the XIth International Hippocrates Colloquium, University of Newcastle Upon Tyne, 27-31 August 2002. Leiden: Brill.

Forrester, J. 1996. 'If p, Then What? Thinking in Cases', History of the Human Sciences 9: $1-25$.

Frank, A. W. 1995. The Wounded Storyteller. Chicago: The University of Chicago Press.

Good, B. 1994. Medicine, Rationality, and Experience. Cambridge: Cambridge University Press.

Greenhalgh, T. and B. Hurwitz. 1999. 'Narrative Based Medicine: Why Study Narrative?', British Medical Journal 318: 48-50.

Grmek, M. 1996. Il Calderone di Medea. Rome-Bari: Laterza.

Harris, W. V. 2016. 'Popular Medicine in the Classical World', in W. V. Harris (ed.), Popular Medicine in the Graeco-Roman World: New Approaches. Leiden: Brill, 1-64.

Hellweg, R. 1985. Stilistische Untersuchungen zu den Krankengeschichten der Epidemien Bücher I und III des Corpus Hippocraticum. Bonn: Dr. Rudolf Habelt GmbH.

Horstmanshoff, M. (ed.). 2010. Hippocrates and Medical Education. Selected Papers presented at the XIIth International Hippocrates Colloquium, Universiteit Leiden, 24-26 August 2005. Leiden: Brill. 


\section{Chiara Thumiger}

Hunter, K. M. 1991. Doctors'Stories: The Narrative Structure of Medical Knowledge. Princeton, NJ: Princeton University Press.

Jaeger, W. 1944. Paideia. The Ideals of Greek Culture: Volume III: The Conflict of Cultural Ideas in the Age of Plato. Oxford: Oxford University Press.

Jouanna, J. 1999. Hippocrates; translated by M. B. DeBevoise. Baltimore, MD and London: Johns Hopkins University Press.

Langholf, V. 1990. Medical Theories in Hippocrates: Early Texts and the Epidemics. Berlin: De Gruyter.

- 2004. 'Structure and Genesis of Some Hippocratic Treatise', in H. F. J Horstmanshoff and M. Stol (eds.), Magic and Rationality in Ancient Eastern and Graeco-Roman Medicine. Leiden: Brill, 219-75.

Lonie, I. M. 1983. 'Literacy and the Development of Hippocratic Medicine', in F. Lasserre and P. Mudry (eds.), Formes de Pensée dans la Collection Hippocratique. Geneva: Droz, 145-61.

Lichtenthaeler, C. 1994. Neuer Kommentar zu den ersten zwölf Krankengeschichten im III Epidemienbuch. Stuttgart: Hermes.

Lloyd, G. E. R. 2009. 'Galen's Unhippocratic Case-Histories', in C. Gill, T. Whitmarsh and J. Wilkins (eds.), Galen and the World of Knowledge. Cambridge: Cambridge University Press, 115-31.

Manetti, D. 1990. 'Data-Recording in Epid. II, 2-3: Some Considerations', in P. Potter, G. Maloney and J. Desautels (eds.), La Maladie et les Maladies dans la Collection Hippocratique. Québec: Les éd. du Sphinx, 143-58.

Miller, G. 1991. 'Literacy and the Hippocratic Art: Reading, Writing and Epistemology in Ancient Greek Medicine', Journal of the History of Medicine and Allied Sciences 45: $11-40$.

Norman, G. R., van der Vleuten, C. P. M. and D. I. Newble. 2002. The International Handbook of Research in Medical Education. Dordrecht, The Netherlands: Springer.

Oikonomopoulou, K. 2015. 'The Problemata's Medical Books: Structural and Methodological Aspects', in R. Mayhew (ed.), The Aristotelian Problemata Physica. Leiden: Brill, 61-78.

Taplin, O. 2000. Literature in the Greek and Roman Worlds: A New Perspective. Oxford: Oxford University Press.

Thumiger, C. 2015a. 'Mental Insanity in the Hippocratic Texts: A Pragmatic Perspective', Mnemosyne 68: 210-33.

. 2015b. 'Patient Function and Physician Function in the Epidemics Cases', in G. Petridou and C. Thumiger (eds.), Homo Patiens: Approaches to the Patient in the Ancient World. Leiden: Brill, 107-37.

- 2016. 'Fear, Hope and the definition of Hippocratic Medicine', in W. V. Harris (ed.), Popular Medicine in the Graeco-Roman World: New Approaches. Leiden: Brill, 198-214.

2017a. A History of the Mind and Mental Health in Classical Greek Medical Thought. Cambridge: Cambridge University Press.

- 2017b. forthcoming. 'The Patient-Doctor Relationship', in P. Pormann (ed.), Cambridge Companion to Hippocrates. Cambridge: Cambridge University Press. 